\title{
Critical Review of the Pharmacoinvasive Strategy Versus Primary Angioplasty in Patients with Acute ST- Segment Elevation Myocardial Infarction
}

\author{
Soto Páramo Dejanira Georgina* \\ Family Physician, Mexican Institute of Social Security, Salamanca, Guanajuato, Mexico \\ *Corresponding author: Soto Páramo Dejanira Georgina, Family Physician, Mexican Institute of Social Security, Salaman- \\ ca, Guanajuato, Mexico
}

ARTICLE INFO ABSTRACT

Received: 慧 May 11, 2021

Published: 彗 May 19, 2021

Citation: Soto Páramo Dejanira Georgina. Critical Review of the Pharmacoinvasive Strategy Versus Primary Angioplasty in Patients with Acute ST-Segment Elevation Myocardial Infarction. Biomed J Sci \& Tech Res 35(5)-2021. BJSTR. MS.ID.005774.
Keywords: Acute Myocardial Infarction; Thrombolysis; Pharmacoinvasive Strategy

Abbreviations: CVD: Cardiovascular Diseases; AMI: Acute Myocardial Infarction; OECD: Organization for Economic Cooperation and Development; PTCA: Primary Percutaneous Transluminal Coronary Angioplasty

\section{Opinion}

"Time is Myocardium", more than a phrase or slogan is an implicit reminder for health personnel about the importance of detecting and treating patients with ST-Segment Elevation Acute Myocardial Infarction (STEMI) in a timely manner to offer them the patient a better prognosis and better quality of life. Cardiovascular diseases (CVD) are the leading cause of death worldwide, and it is estimated that 17.9 million lives are claimed each year, since 2020 the number of deaths due to heart disease has increased by 2 million people 9 million people in 2019. CVDs include: coronary heart disease, cerebrovascular disease, heart disease, rheumatic disease among others. Four out of 5 CVD deaths are due to strokes, and a third of these deaths occur prematurely in people under 70 years of age. $80 \%$ of Cardiovascular Diseases (CVD) and Acute Myocardial Infarction (AMI) are preventable, as well as more than $75 \%$ of deaths caused by CVD occur in low- and middle-income countries [1]. In Mexico, various strategies are carried out to carry out a rapid response and timely treatment of AMI, following the Infarction Code protocol and the National Program for the Reduction of Mortality from Acute Myocardial Infarction AMI-MX (PREMIA), position that Mexico has a hospital mortality rate from AMI three times higher than the average of the Organization for Economic Cooperation and Development (OECD) countries (28.1 vs. 7.5 deaths per 100 discharges) in 45-year-old patients. age and over and 1 in 2 patients with AMI do not receive any type of reperfusion therapy, as well as 1 in 4 unfortunately dies [2].

In November and December 2016, a telephone survey was carried out on patients who had suffered an AMI between 2015 and 2016, being treated in hospitals of the Ministry of Health, information was collected on pre-hospital care and their medical care, 120 patients were identified, most were under 60 years old; $62 \%$ did not seek immediate medical attention because they were unaware of the symptoms of AMI, the majority occurred at home, $50 \%$ of the patients took more than 30 minutes to request medical attention and also half were seen in the emergency services, $32 \%$ went to a private clinic or clinic, $86 \%$ were seen immediately, but only 58\% had an initial electrocardiogram (EKG) performed, the 
diagnosis was immediate in $77 \%$; half were provided with an emergency procedure, $80 \%$ were referred to a second hospital for medical attention; $24.6 \%$ were transferred to a third site for their attention. Only 1 in 3 patients started specialized treatment within 5 hours, with respect to treatment, $74 \%$ underwent catheterization, $8 \%$ thrombolysis and 6\% primary angioplasty [3]

To reduce the unfortunate mortality from heart disease, it is imperative to apply the pharmacoinvasive strategy (PS) in the patient with STEMI, together with the change in logistics, infrastructure, access to medicines and supplies, and transportation. Centers capable of offering primary PCI 24 hours a day, 7 days a week (24/7) must be in place and started as soon as possible. It is recommended to define an area under observation for the diagnosis and treatment of patients with infarction. Depending on the characteristics of the service, it may be within the shock, resuscitation section or close to it, the area must be directly accessible with a chest pain bed, which will preferably be exclusively for this purpose, being essential to have a 12-lead electrocardiograph in the area (preferably 3-channel), as well as a medical crash cart with cardiopulmonary resuscitation equipment, supplies and first-line drugs [4].

The objective of reperfusion therapy is to restore the coronary flow of the artery responsible for the infarction and guarantee the patency of the vessel. There are two types of therapy that can be used in the reperfusion of

STEMI: pharmacological reperfusion with a fibrinolytic agent (a drug that achieves the lysis of the coronary thrombus) and primary percutaneous transluminal coronary angioplasty (PTCA), which allows to know the coronary anatomy and directly reach and guarantee the flow of the vessel $[5,6]$. Pharmacological reperfusion with a fibrinolytic, indicated within the first 12 hours from the onset of symptoms in STEMI by EKG, without the presence of contraindications, without the availability of a Hemodynamics room (Level of Evidence 1A) Fibrinolytics can be divided into two groups: $[4,7]$.

a. "Non-fibrinospecific" activators such as SK, urokinase, and anistreplase. These act on plasminogen, both circulating and attached to the clot, converting it into plasmin. They produce fibrin lysis in the clot, but also generate significant systemic fibrinogenolysis, with fibrinogenemia and elevation of circulating fibrin degradation products [7].

b. The "fibrinospecific" activators (t-PA, single-chain urokinase-type plasminogen activator scu-PA, reteplase, tenecteplase), which by virtue of their relative selectivity for the binary plasminogen-fibrin complex give rise to fibrin lysis on the surface of the clot without theoretically affecting to circulating fibrinogen [7].

The pharmacoinvasive strategy (PS0) is defined as fibrinolysis combined with subsequent Percutaneous Coronary Intervention
(PCI) (indicated within the first 2 to 24 hours after thrombolysis, in successful thrombolysis) to ensure the patency of the blood vessel, evaluated in studies such as GRACIA-29 This strategy is particularly useful in patients who cannot meet the goal of 120 minutes (this being the maximum transfer time of the patient from a hospital with a coronary unit) [6,8]. The SHOCK study compared an urgent reperfusion strategy obtained by Primary angioplasty or surgery against an initial medical stabilization strategy, including intraaortic balloon pump (IABP) and fibrinolysis. Urgent mechanical reperfusion obtained an absolute reduction in mortality of 9 points at 30 days, which did not reach statistical significance, but the difference increased to 13 points with statistical significance at six months (mortality of 50.3 versus 63.1, p = 0.027). Emergency bypass surgery is reserved for particularly complex anatomical situations and is rarely used in clinical practice (less than $10 \%$ of patients in a United States national registry [9]. Many patients do not achieve the time goals for treatment, according to the STEMI guidelines which recommend times: door-to-needle $<30 \mathrm{~min}$ for fibrinolysis and door-to-balloon $<90 \mathrm{~min}$ in case of PTCA. Due to logistics and geographical issues, particularly in Mexico there are few hemodynamic rooms (only $15 \%$ of hospitals have one), and most are not available 24 hours a day. Although it has been demonstrated that PCI is the treatment of choice in STEMI. ICPP-related delay diminishes benefit; the magnitude of the benefit in mortality and cardiac muscle salvage is greater the earlier treatment is started.

This is why reducing delays until the start of therapy is vital to improve the prognosis of patients with STEMI5 $[5,6,10]$. In the study of Sierra Fragoso a relatively frequent complication of AMI was excluded, that is, Cardiogenic shock, which would have provided valuable information regarding the status and hemodynamic management of the patients. Cardiogenic Shock (CS) had its first description of cardiogenic shock in 1942 by Stead and Elbert and its most common cause is IAMSCESST, likewise 70 years after that first description, CS continues to be the main cause of death in AMI in the hospital stage, its mortality has decreased in the last two decades but remains high, between $40 \%$ and 50\% despite percutaneous coronary reperfusion, optimal medical therapy and mechanical circulatory support [9]. It also lacks to know clinical variables (cardiovascular risk factors, clinical picture, somatometry, hemodynamics such as mean arterial pressure, cardiac output) as well as laboratory variables to cover not only a population sector but also to have a broader dimension and a coarser universe In addition, there is a lack of information on arrival times, needle gate, balloon gate, to know the time of care and make comparisons, investigation of the time relationship, reperfusion therapy and its result, short and medium term prognosis and within complications, CS as already mentioned previously.

The cited study focused on describing the characteristics of PCI, PTCA, such as vascular accesses: radial, femoral, stent 
placement, IABP, temporary pacemaker, but it does not describe the thrombolysis used in the pharmacoinvasive therapy of the patients to whom it was administered, that is, the type of fibrinolytic, the dose, etc. is unknown, it would also have been important to know it, having a broad vision of the drugs and conducting research of its repercussion not only at the level of response to treatment but also the prognosis of the patients.

Early coronary reperfusion is the essence of the treatment of Acute Coronary Syndrome (ACS) and the main factor that has contributed to the decrease in mortality in these patients. Observational studies have shown that when the artery responsible for AMI is open in ACS, regardless of the reperfusion method, mortality is reduced to less than half (75\% to $33 \%)$ [9].

\section{Conclusion}

The implementation of a Pharmacoinvasive strategy should not be only an option but should be implemented as optimal management for rescue in STEMI, since generally the treatment goals are not achieved due to various situations of logistics, resources, infrastructure and geography. maximum if percutaneous coronary intervention is not achieved in the first 120 minutes as previously established, especially in these times of the COVID19 pandemic where, due to the same cause of the SARS COV2 virus, patients did not attend an assessment for fear of contagion, the health personnel working to the limit, the administrative management of human resources, supplies, training, etc. The advent and implementation of the Pharmacoinvasive Strategy is carried out in favor of the improvement of the patient, for a favorable prognosis and improvement in their quality of life, safeguarding life itself wide mission in medicine and I quote Hippocrates "Wherever the art of Medicine is loved, there is also a love of Humanity".

\section{References}

1. World Health Organization Cardiovascular Diseases.

2. Torres Ornelas P, Luna Martinez J (2018) Letalidad del Infarto Agudo del Miocardio en los Servicios de Salud del Estado de Colima. Metodología y Procesos CONAMED 3(1): 8-9.

3. García Saisó S (2017) La Atención del Infarto agudo al Miocardio en México. Estudio de oferta y demanda y análisis económico ex ante de un Programa Nacional de Reducción de la Mortalidad por Infarto Agudo al Miocardio, Secretaria de Salud, p. 11-17.

4. Borrayo Sánchez G, Pérez Rodríguez G, Martínez Montañez OG, Almeida Gutiérrez E, Ramírez Arias E, et al. (2017) Protocolo para urgencias: Código infarto. Rev Med Inst Mex Seguro Soc 55(2): 233-246.

5. Martinez Ríos M (2017) IAM-MX" Sociedad Mexicana de Cardiología, p. 3-11.

6. Sierra Fragoso ÁA, Galván García JE, Vargas Ramírez JF, Arboine Aguirre LA, Muñoz Consuegra CE, et al. (2018) Estrategia farmacoinvasiva versus angioplastia primaria en pacientes con infarto agudo al miocardio con elevación del segmento ST. Rev Mex Cardiol 29(3): 126-133.

7. Junker G (2013) Tratamiento fibrinolítico en el infarto agudo de miocardio. Rev Urug Cardiol 28: 430-436.

8. Fernandez Aviles F, Joaquín J Alonso, Gonzalo Peña, Jesús Blanco, Juan Alonso Briales, et al. (2007) Primary angioplasty vs. early routine post fibrinolysis angioplasty for acute myocardial infarction with ST-segment elevation: the GRACIA-2 non-inferiority, randomized, controlled trial. Eur Heart J 28(8): 949-960.

9. Montes De Oca O (2014) Shock cardiogénico en el infarto agudo de miocardio. Rev Urug Cardiol 29: 145-152.

10. García García C, Lluís Recasensa, Nuria Casanovasa, Faustino Mirandaa Francisco Del Bañob, et al. (2008) Reducción del tiempo puerta-aguja a los objetivos de las guías. Pronóstico a un año. Rev Esp Cardiol 61(8): 888-891.

\section{ISSN: 2574-1241}

\section{DOI: 10.26717/BJSTR.2021.35.005774}

Soto Páramo Dejanira Georgina. Biomed J Sci \& Tech Res

cC) (P) This work is licensed under Creative

Submission Link: https://biomedres.us/submit-manuscript.php

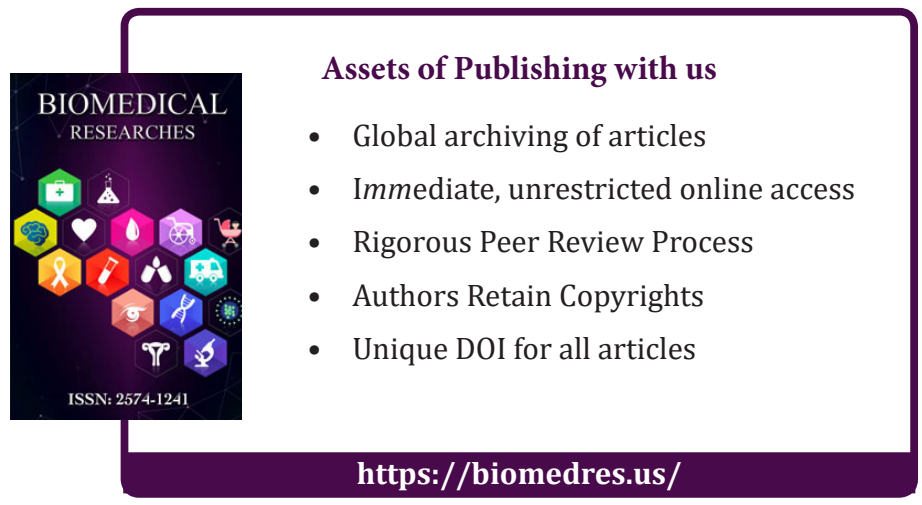

